\title{
Urban maps: instruments of narrative and interpretation in the city
}

Eray Çaylı

To cite this article: Eray Çaylı (2015) Urban maps: instruments of narrative and interpretation in the city, Journal of Urban Design, 20:5, 698-699, DOI: 10.1080/13574809.2015.1106881

\section{BOOK REVIEW}

Urban maps: instruments of narrative and interpretation in the city, by Richard Brook and Nick Dunn, Surrey, Ashgate, 2011, 250 pp., ISBN 978-0-75467-6577

The premise of this book is that from the second half of the twentieth century onwards the perception and experience of space and place have undergone profound changes. It is the various spatial practices and discourses that have negotiated these changes, which Brook and Dunn conceptualize as 'urban maps'. Importantly, such practices and discourses the authors explore come not just from within the conventional confines of the field of architecture but also from artistic practice, and include both historical and contemporary examples.

The introductory chapter discusses two late twentieth and early twenty-first century processes, which the authors argue have been caused primarily by developments in communication technologies and financial systems, and have led to the contemporary urban condition. These two processes are the 'erosion of place' (1-4) and 'confusion of space' (4-7). While the latter refers to the social and material dissolution of the idea of a 'focal point' of human activity, the former indicates the hybridization of functional, symbolic and sponsorship categories in architecture which until recently were thought irreconcilably distinct. The authors then go on to identify 'maps' (7-18), 'motion' (18-30) and 'street art' (30-36) as three forces that intervene into the interstices between the conceptual and material aspects of cities. Importantly, these are forces that have each been traditionally associated with a separate body of knowledge production, respectively: urban design and town planning, on-the-ground experience and exploratory intervention; moreover, a hierarchy between the architectural authority of each has been presumed. However, for Brook and Dunn, the three forces work in tandem and with mutual impact on one another to expose urban relations that are otherwise not always readily visible, and thus together point to a cross-disciplinary array of urban mapping practices.

After laying out the book's premise, Brook and Dunn embark on five core chapters, each of which is themed after a medium employed by the spatial practices and discourses that have engaged with the 'erosion of place' and 'confusion of space'. These themes are brands, networks, films, marks and objects. In bringing together such diverse media, the authors demonstrate that what is at stake is less the idea of maps as passive representations than the practice of mapping as both produced by and productive of the various relationships revolving around the built environment. The medium preoccupying Chapter Two is branding. Through the work of Marshall McLuhan and Quentin Fiore, Robert Venturi, Jean Baudrillard, and Fredric 
Jameson, the authors trace the past five decades' boom in the urban influence and presence of commercially oriented images and identities, as a result of which "aesthetic value has been superseded by sign value" (49). One concrete contribution of this chapter to architectural typology is its grouping of various examples of 'branded architecture' under four types: 'the cardboard box' (73-74), 'the graphic building' (74-75), 'the pure sign' (76-78), and 'the chocolate box' (78). Chapter Three discusses the concept of 'network' which has been put in the limelight due to developments in communication technologies. Building on the work of Guy Debord, Marc Augé, Manuel Castells and Manuel De Landa, the authors chart the recent history of how networks have both infrastructurally and conceptually come to shape architecture and experience in cities. The chapter makes the case for a network-based connectivity that helps people integrate into urban conditions rather than one that causes them to isolate from the latter (114). While the development of the argument in these first two core chapters gives sequential primacy to the discourses surrounding what the authors call the 'erosion of place' and 'confusion of space' and/or the protagonists whose work has precipitated the latter, the authors also discuss the critical and subversive practices that have engaged with these two processes. The latter includes the work of practitioners who appropriate graphic design strategies to counter advertising (69-71), mobilize the potential of brandscapes as an arena for intervention in urban politics (71-72), and utilize the logic and infrastructure of networked surveillance to make latent relations and experiences in the city available to the wider public (108-111).

If in the first two core chapters the sequence in which the authors discuss spatial discourses and artistic practices implicates the former as presiding over the latter, the following three chapters offer a slightly different methodology which helps theoretical engagement emerge more gradually through analyses of practice. Chapter Four turns to cinematic representation, investigating the role of film within the architectural practices of Coop Himmelb(1)au, Rem Koolhaas and Bernard Tschumi, and the role of architecture within the work of filmmakers such as Mike Leigh, Andrea Arnold, Mathieu Kassovitz, Stephen Frears and Michael Winterbottom. The chapter's main argument is that to consider moving images as urban mapping means to shed light on their effective role in capturing the multiplicity of lived urban experience and in revealing layers, conflicts and relationships in cities which may otherwise be concealed behind grander narratives. Chapter Five discusses the two-dimensional imprint that street artists leave on cities. Special attention is given to questions of ethics, safety, legality, access and ownership that so often surround the practice of street art (153-156). The chapter explores relationships mapped out by street art that appropriates infrastructural surfaces (156-161), embraces graffiti's ephemerality (161-162 and 166-168), involves site-specificity or bodily interactions with the built environment (162-164 and 181-183), and engages with the logic of branding either visually or through sponsorship (162-163 and 169-179). Themed 'Objects', Chapter Six, follows from the previous one but looks into art that yields three-dimensional results. This allows for a much more materially conspicuous discussion of art's site-specificity and its relationship to context, and, more specifically, of the dynamics and/or transition between the spaces of studio, gallery, 
museum and street. As the chapter concludes by discussing urban artworks' operation as and through networks (216-222), and the oscillation between what the authors call 'unregulated' and 'hyper-regulated' types of architecture (222-226), the authors seem intent on bringing full circle some of the fundamental questions preoccupying the book since its outset.

The strength of Urban Maps lies in its cross-disciplinary, cross-scale, cross-historical and crossmedia approach to discussing the ways in which recent developments in communication technologies and financial systems have impacted on the built environment and experience of cities. Where it falls short has to do with some of the discourses and narratives surrounding the developments in question, such as those concerning decentralization and the networked society. At times, the authors all too unsuspectingly base their arguments and analyses of practice on these discourses and narratives rather than re-evaluate the latter through the former, especially in the Introduction and the first two core chapters. That is not to say that this overshadows the book's numerous strengths. It is to suggest that Brook and Dunn's primary audience seems to comprise urban designers and architects rather than those interested in urban theory. Indeed, the book promises to be an excellent teaching resource, especially in the case of practice-oriented students in urban design and architecture. 